\title{
Water is Life
}

\section{Clean Water for Native American Tribes}

HEATHER TANANA FOR ACADEMIC MINUTE

Water is life. Every household in America needs and is entitled to clean and safe water access. Yet, the magnitude of lack of clean water access in Indian country is significant and startling. Our report uncovers the four main factors that have exacerbated gaps in tribal drinking water access, and in turn hurt public health and economic growth:

First, Lack of piped water services-Native American households are more likely to lack piped water services than any other racial group. Navajo residents, in particular, are 67 times more likely than other Americans to live without access to running water. Hauling water is not only more expensive than piped water, but also increased the risk of exposure to COVID-19 during the pandemic.

The second component is inadequate water quality-poor quality is pervasive in Indian Country. The Hopi Tribe, which has struggled with arsenic contamination since the 1960s, estimates that approximately 75 percent of people living on Hopi land are drinking contaminated water.

Third, deteriorating or inadequate water infrastructure contributes to water insecurity -infrastructure investments haven't kept up with need, resulting in interruptions in service and potential contamination of supplies. Some tribes have water systems dating back to the late 1800s. Native Americans are one of the youngest and fastest growing populations. Yet, because of deteriorating infrastructure, Tribes are struggling to support their growing communities.

Finally, many tribes are encountering challenges in supporting operation and maintenance costs putting existing water systems are at risk. Additional resources and tribal capacity are necessary to avoid future disruptions to water service in the community.

Now's the time for the federal government to keep its promises to Indian country and ensure that all Americans have access to clean, safe, and reliable drinking water. 

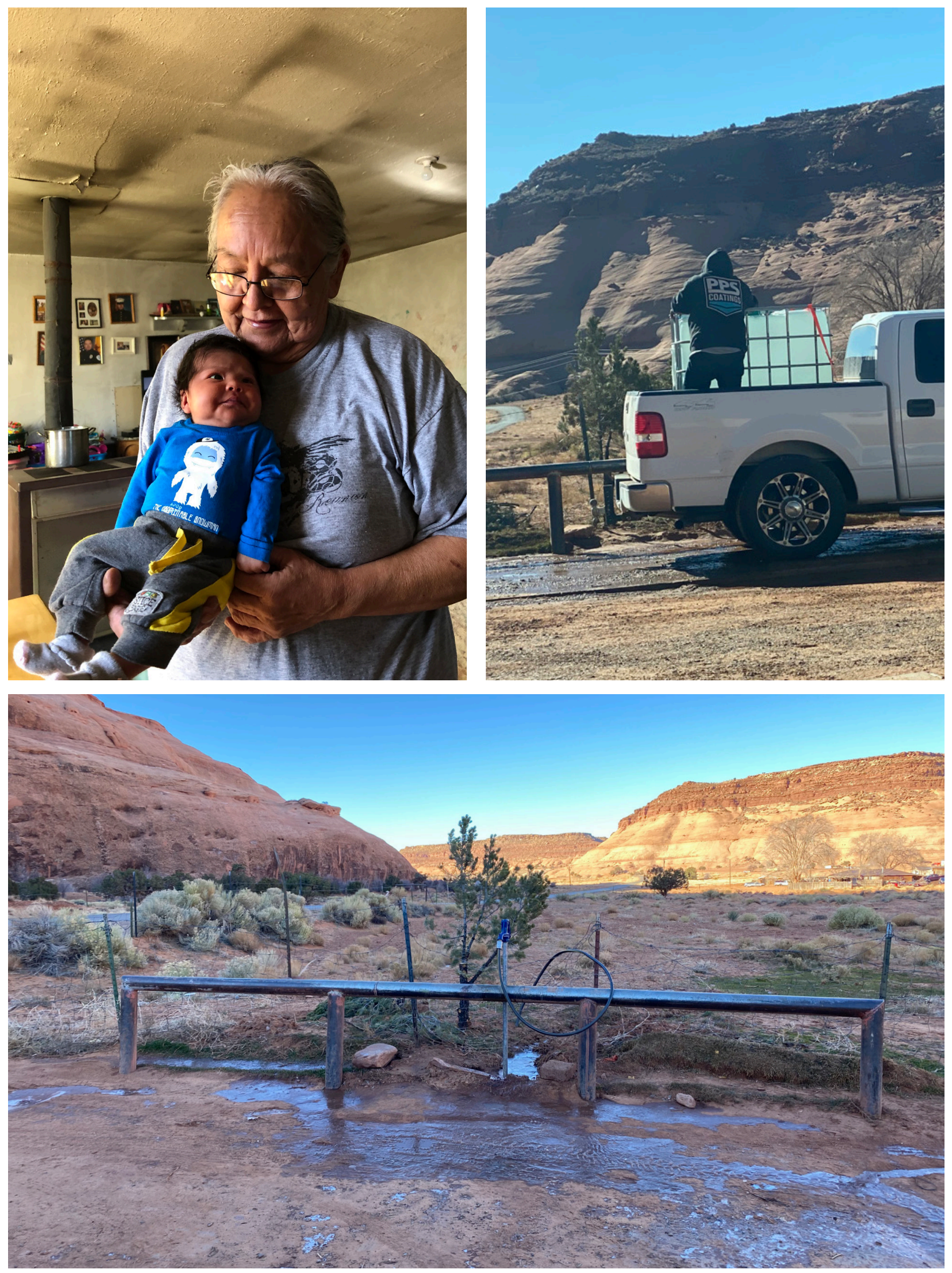